\title{
ФОЛЬКЛОРНЫЕ И КУЛЬТУРНЫЕ ОСОБЕННОСТИ ЭТНИЧЕСКОЙ ИДЕНТИЧНОСТИ ОРОЧОНОВ И МАНЬЧЖУРОВ, ПРОЖИВАЮЩИХ ИЗ ПОКОЛЕНИЯ В ПОКОЛЕНИЕ В ПРОВИНЦИИ ХЭЙЛУНЦЗЯН'
}

\section{FOLKLORE AND CULTURAL FEATURES \\ OF THE ETHNIC IDENTITY OF THE OROCHONS AND MANCHUS LIVING FROM GENERATION TO GENERATION IN HEILONGJIANG PROVINCE}

Tan Yanhui

Zhang Yang

Summary: Ethnicidentity, formed in the minds of people, includes various cultural characteristics and determines the life-affirming positions of each person (belonging to a particular people), characteristic of the entire group and transmitted from generation to generation throughout ethnic history, which is expressed in a sense of belonging to a particular community and is reflected in ethnic ties.

This article provides a theoretical analysis of the specifics of the origins of the ethnic identity of the Orochons (Orochens) and Manchus living in the lands of north-eastern China. Speaking about the historical transformations of the worldview of the indigenous population of Heilongjiang province and its leading ideas, it should be noted that the signs and evidence of the formation of the ethnic phenomenon of the described peoples are displayed mainly in the culture and, as a result, in the oral folk art of the Manchus and Orochons, as evidenced by religiousmythological, folklore-mythological and religious narratives. At the same time, the folklore traditions of the studied peoples, which since ancient times structure the ideas of the inhabitants of the Chinese province about the origin of the world and man, as well as consolidate their significant ideas about ethnogenesis, are considered by the authors in the system of the formation of their ethno-culture.

Keywords: folklore, culture, ethnic identity, Orochon (Orochen), Manchus, Heilongjiang Province.

\author{
Тань Яньхуэй \\ Библиотекарь, Университет г. Хэйхэ \\ Чжан Ян \\ Благовещенский государственный педагогический \\ университет, г. Благовещенск; библиотекарь \\ Университета г. Хэйхэ \\ 1684929245@qq.com
}

Аннотация: Этническая идентичность, формируемая в сознании людей, включает в себя различные культурообразующие характеристики и предопределяет жизнеутверждающие позиции каждого человека, (принадлежащего к конкретному народу), характерные для всей группы и передающиеся из поколения в поколение на протяжении всей этнической истории, что выражается в чувстве принадлежности к конкретной общности и отражается в этнических связях.

В данной статье проводится теоретический анализ специфики истоков этнического самосознания орочонов (ороченов) и маньчжуров, проживающих на землях северо-восточного Китая. Говоря об исторических трансформациях мировоззрения коренного населения провинции Хэйлунцзян и его ведущих идеях, следует отметить, что признаки и свидетельствования о формировании этнического феномена описываемых народов отображаются, преимущественно, в культуре и, как следствие, в устном народном творчестве маньчжуров и орочонов, о чем свидетельствуют религиозно-мифологические, фольклорно-мифологические и религиозные повествования. При этом фольклорные традиции исследуемых народов, которые с глубокой древности структурируют представления жителей китайской провинции о происхождении мира и человека, а также закрепляют значимые для них представления 06 этногенезе, рассматривается авторами в системе становления их этнокультуры.

Ключевые слова: фольклор, культура, этническая идентичность, орочоны (орочены), маньчжуры, провинция Хэйлунцзян.

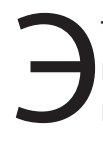
тническая идентичность личности (этнический феномен) включает в себя не только культурообразующие характеристики (традиции, обычаи, понятия, религию, почитание и пр.), но и предопределяет «понимание человеком «правил жизни», диктуемых ему социальными и природными силами» [1, с. 28], что включает в себя установки, особенности поведения и жизненного уклада, характерные для всей группы и передающиеся из поколения в поколение.

Дифференцируя население определенных территорий согласно их племенному родству / различию, пре-

Авторы выражают благодарность проекту специального фонда университета Хэйхэ для основных научных исследований университетов в провинции Хэйлунцзян в 2020 году (название проекта: «Исследование обычаев и нравов малых народностей вдоль побережья Хэйлунцзян на примере орочонов и маньчжуров»; код: 2020-KYYWF-0876). 
жде всего, обращается «внимание на язык, а затем уже - на физические свойства народа» [2, с. 37]. «Этническая картина мира, в свою очередь, отображает воззрения личности на окружающую действительность, которые характерны для него, как представителя конкретного населения» [1, с. 28].

Исходя из концепции Б.Е. Виннер (2005), С.А. Подъяпольского (2013), а также солидарных с ними Е.В. Матвеевой и Е.Б. Сергеевой (2019), «при разговоре об этносе подразумевается, что у людей, которые объединяются, выделяя себя из внешней среды, существует корреляция между этнической идентичностью и переменными («признаками» этноса)» [3, с. 143; 5, с. 665; 12, с. 5]. В данной статье речь идёт о фольклорных и культурных особенностях народов провинции Хэйлунцзян (этнонимы: орочоны и маньчжуры), которые выступают в роли вышеобозначенных «этнических переменных».

Согласно научным трудам Г.М. Василевич (1969), орочоны и маньчжуры входили в одну из четырёх групп тунгусских племён китайского Приамурья и составляли южную ветвь [2, с. 37]. При этом, по замечанию исследователей, маньчжуры и орочоны являлись контактной группой населения, вследствие чего можно было ознакомиться и получить достоверные сведения об их фольклорных и культурных особенностях [7, с. 5].

Говоря об их этнической принадлежности, важно подчеркнуть, что до конца первой четверти XX в. наблюдалась стойкая ситуативная идентичность данных народов, а именно, свою национальность представители племён называли в зависимости от того, какую, по их мнению, могло это принести им экономическую или другую выгоду, либо, напротив, как это может уберечь их от негативных последствий [9, с. 126]. Например, буряты называли оленных эвенков-орочонов (орочонов, занимавшихся оленеводством) хамнеганами, а «баргузинские эвенки только на вопрос бурята могли назвать себя хамнеган, но сами называли себя эвенками» [8, с. 49].

Об образах мироздания народов провинции Хэйлунцзян свидетельствуют их космогонические фольклорно-мифологические повествования, формировавшие этническое самосознание орочонов и маньчжуров [11, с. 47]. Согласно их дуалистическим представлениям: Вселенную, людей и животных, небесные светила и природные явления, а также духов и божеств всех объектов мироздания, сотворили два брата: Буга и Бунинка (хозяин мира мертвых и огня) [10, с. $54-55 ; 6$, с. 168]. По мнению И.Г. Георги (2005): «Верховное, или всеобщее, божество называли Боа, а дьявола - Буги» [4, с. 328]. А, например, «в маньчжурском пантеоне дух смерти Доксиньту Эндури принадлежал свите верховного владыки подземного мира Илмун хана (Захаров, 1875)» [6, с. 520].
Фундаментообразующим концептом самобытности и традиционной культуры, соответственно, фольклора данных племён была охотничья и животноводческая (преимущественно оленеводчество или коноводчество) жизнедеятельности, ввиду чего в устном народном творчестве преобладали образы животного мира, формируемые согласно тем особям, что населяли территорию провинции Хэйлунцзян и регулярно тем или иным образом взаимодействовали с людьми: собаки, олени, кони, лоси, колонки, волки, росомахи, рыси, медведи и кабаны [2].

Очень важно подчеркнуть, что в мифах данных групп населения «волк фигурирует как один из помощников творца», [2, с. 223] - данный аспект сформировал представление народов провинции Хэйлунцзян о том, что хищник стал «одним из посредников между творцом и людьми» [Там же]. Согласно этим воззрениям, слагались рассказы о волке-человеке, таким образом, к примеру, в орочонской мифологии божества представлялись, как правило, в антропоморфном облике, включающем зооморфные компоненты.

У маньчжуров происхождение человека фигурирует в тотемистических мифах об иве и женском божестве Фото-маме (Фохэ-маме), в которых она описывается в роли первотворца и объекта почитания детородной силы $[12$, с. 18$]$.

Говоря о фольклоре орочон, отображающих культуру народа, следует отметить, что для них было несвойственно охотиться на волка. Как отмечает К. Рычков в своих записях, собранных благодаря рассказам илимпийских эвенков (эвенков-орочонов): пути к верхнему божеству (хэвэки) знают только волк и ворон: «волк считался помощником, вместе с вороном верхнего духа Сэвэки» [2, с. 230 - 231; 8, с. 506], чьё имя запрещалось произносить вслух, в противном случае мог появиться волк. По мнению забайкальских орочон, как подчеркивает в своих исследованиях Малых, «волк все равно, что орочон», т.е. «все равно, что брат». Также в фольклорных записях Г.М. Василевич (1969) от алданскнх орочонов имеется запись о том, что «волк был раньше человеком». А орочоны с Чары не били волка из страха его мести. Такое представление о волке, по-видимому, появилось от монголов, когда орочоны жили с ними по соседству [2, с. 61].

При этом Сэвэки сопоставляли с образом молодого солнца. Помимо которого орочоны верили в бабушкусолнце (Энекан Сигун), светившее на протяжении всей зимы и накапливавшее на протяжении всего сезона в своей юрте тепло, которое по весне изливалось на Землю [7, с. 109].

В обоих исследуемых нами народах существовал культ предков и императоров. Говоря о происхождении последних, следует подчеркнуть превалирование тоте- 
мистических мифов, повествующих о происхождении властителей (например, у маньчжуров известен миф о рождении императорского клана Айсинь Гиёро) $[12$, с. 18]. Также к устному народному творчеству маньчжуров и орочонов целесообразно отнести сказки, легенды, предания и пр., «объясняющие» существование окружающего мира и его законы.

Выводы: культура и, как следствие, образы устного народного творчества орочонов и маньчжуров складывались согласно природно-ресурсному потенциалу провинции Хэйлунцзян.

Этногенез и историческая судьба исследуемых народов, соответственно, их этническая идентичность, опирались на космогонические фольклорно-мифологические повествования, в которых отображались концепты бытия человечества, начиная с мироздания, оканчивая принципами взаимоотношений «современных» людей с божествами, духами, природным и животным мирами.

Дикие звери и домашние животные в фольклоре возникали в зависимости от местности и природообразующих компонентов, для которых было свойственно их проживание (тайга или степь). Взаимодействие людей с природой описывалось в тотемистических мифах, которые слагались, опираясь на промыслы древних поселений Хэйлунцзян (охота и животноводство).

Таким образом этническая идентичность орочонов и маньчжуров прослеживается в фольклоре и культуре народов сквозь призму почитания природы и корреляции человека и животных, от которых зависела жизнь, судьба и благополучное существование жителей провинции Хэйлунцзян.

\section{ЛИТЕРАТУРА}

1. Бабунова, Е.С. Основы этнопсихологии и этнопедагогики [Текст]: учебное пособие / Е.С. Бабунова. - 2-е издание, стереотипное. - М.: ФЛИНТА, 2015. 152 c.

2. Василевич, Г.М. Эвенки [Текст]: Ист.-этногр. очерки (XVIII - начало XX в.) / АН СССР. Ин-т этнографии им. Н.Н. Миклухо-Маклая. - Л.: Наука. Ленингр. отдние, 1969. - 304 с.

3. Винер Б.Е. Формы этничности, бывает ли у этноса сущность и что сторонники академика Бромлея могут взять у новых теорий // Журнал социологии и социальной антропологии. - 2005. - Т. 8. - № 2. - С. 143.

4. Георги И.-Г. Описание всех обитающих в Российском государстве народов. СПб.: Русская симфония; Библиотека АН, 2005. - 816 с.

5. Подъяпольский С.А. Понятие этноса: социально-философская дефиниция // М.: Современные проблемы науки и 0бразования. - 2013. - №5. - С. 665.

6. Сем, Т.Ю. Картина мира тунгусов: пантеон (семантика образов и этнокультурные связи): историко-этнографические очерки. - СПб.: Филологический факультет СПбГУ, 2012. - 626 с.

7. Сем, Т.Ю. Верховный пантеон тунгусо-маньчжурских народов Сибири и Дальнего Востока (XIX-XX вB.): типология и семантика образов: дис. ... кандидата исторических наук: 07.00.07 / Сем Татьяна Юрьевна; [Место защиты: Рос. гос. пед. ун-т им. А.И. Герцена]. - СПб., 2007. - 245 с.

8. Сирина, А.А. Проблемы типологии и преемственности этнических культур эвенков и эвенов: конец XIX - начало XXI веков: дис. ... доктора исторических наук: 07.00.07 / Сирина Анна Анатольевна; [Место защиты: Ин-т этнологии и антропологии РАН]. - М., 2011. - 608 с.

9. Сирина, А.А. Эвенки и эвены в современном мире [Текст]: Самосознание, природопользование, мировоззрение / А.А. Сирина; Российская акад. наук, Ин-т этнологии и антропологии им. Н.Н. Миклухо-Маклая. - М.: Восточная лит., 2012. - 604 с.

10. Спасский Г. Забайкальские тунгусы // Сибирский вестник. СПб., 1822. С. 54-55.

11. Чжан Линьбэй. Исторические трансформации и современное состояние религиозных традиций маньчжуров северо-восточного Китая: дис. ... кандидата философских наук: 09.00.14 / Чжан Линьбэй; [Место защиты: Амур. гос. ун-т]. - Благовещенск, 2011. - 179 с.

12. Этнокультурные технологии: учебное пособие по направлению подготовки 51.03 .03 Социально-культурная деятельность, уровень подготовки - бакалавриат / ФГБОУ ВО «Восточно-Сибирский государственный институт культуры»; [сост.: Е.В. Матвеева, Е.Б. Сергеева]. - Улан-Удэ: ФГБОУ ВО ВСГИК, 2019. -86 c. 